\title{
ONTWRONGEN BEZWAREN
}

DOOR

G. J. STAAL

De Ondernemersraad voor Suriname, broeder van den gelijknamigen Raad voor Ned.-Indië, heeft in druk doen verschijnen een „Rekest aan den Minister van Koloniën dd. 22 Juli 1926 met daarbij behoorende Nota", waarin het instituut de noodzakelijkheid betoogt om zoo spoedig mogelijk krachtige pogingen te doen tot eene blijvende verbetering van de zoo zeer gedrukte economische omstandigheden van Suriname en zich bereid verklaart van zijn kant daartoe mede te werken door opwekking van het in Oost-Indië werkend kapitaal ten bate van de West, mits Opperbestuur en Staten-Generaal de wettelijke hervormingen willen bevorderen en de geldelijke offers willen brengen, die de in de Nota aanbevolen maatregelen vragen.

Hartelijk verheug ik mij in dit optreden van den Ondernemersraad; even hartelijk hoop ik, dat de Raad er in slagen moge eindelijk eens aan Suriname te bezorgen wat het land behoeft om tot ontwikkeling te komen.

Des te meer doet het mij leed, dat ik ernstig bezwaar moet maken. niet tegen de voorstellen van den Raad, doch tegen dat deel van de beschouwingen in de nota, dat niet geheel strookt met de werkelijkheid en waarin aan den Gouverneur, die in 1920 den maatstaf der loonen van de contract-arbeiders op de plantages verhoogde, handelwijzen worden aangewreven, hem eene onbedachtzaamheid wordt verweten en aan zijne beslissing in zake de loonen gevolgen worden toegeschreven, die een geheel verkeerden indruk moeten wekken van den loop van zaken. 
Ik bedoel de bladzijden 40 en 41 der Nota en de daar gegeven uiteenzetting van de loonsverhooging.

De Gouverneur, die haar invoerde, is schrijver dezes.

Een persoonlijk verweer dus? Best! De subjectieve tint van dit deel der nota moge het verklaren. Maar men onderschatte niet deze zakelijke overweging: dat het in het belang van den uitslag der bemoeienissen van den Ondernemersraad noodig en nuttig is tegenover diegenen, die geneigdheid mochten voelen aan den economischen opbouw van Suriname mede te werken, te doen uitkomen dat het daarginds wezenlijk niet zoo willekeurig en onbenullig toegaat als zij misschien uit de verschafte voorlichting zouden afleiden, tot schade voor hunne goede voornemens.

Zooals in de Nota is medegedeeld, is het loon der immigranten op de plantages, - dat zijn: de Oosterlingen, die met eene werkovereenkomst in Suriname worden aangevoerd voor landbouwarbeid; vroeger Britsch-Indiërs en Javanen, thans alleen Javanen, - in 1920 verhoogd van $f 0.60$ tot $f 0.80$ voor den man, van $f 0.40$ tot $f 0.60$ voor de vrouw per werkdag. Het zou beter zijn te spreken van den maatstaf van het loon, die verhoogd werd: de immigranten werken namelijk voor het meerendeel op taak en niet op tijd. Het loon beteekent voor hen dus het bedrag, dat hun toekomt voor het volbrengen van zekere taak, welke de werkgever verplicht is, onder Overheidstoezicht, zoodanig vast te stellen, dat de arbeider die taak kan afwerken, en derhalve het volle bedrag kan verdienen, binnen den wettelijk bepaalden arbeidstijd. Het werkelijk verdiende loon kan méer of minder zijn dan het maatstaf-, het standaardloon; minder, als de arbeider zijne taak in den werkdag niet afmaakt; méer als hij méer werk volbrengt, of ook als de taak bijzondere inspanning of vaardigheid vordert en op dien grond hooger getarifiëerd is.

De hiervoren genoemde bedragen van 80, 60 en 40 cent zijn de normale maatstaf-minima voor eene dagtaak. De werkgever is gehouden in elk geval zooveel werk aan te bieden aan den immigrant, dat deze het minimum kan behalen. Dat minimum is tevens het dagloon voor werk 
op tijd. Het vertegenwoordigt dus eene loon-garantie.

De 60 cent voor den man en de 40 cent voor de vrouw dagteekenen reeds van omstreeks 1870 . Het kan dus niet verwonderen, dat die maatstaf een halve eeuw later niet meer in den tijd paste, noch dat in den loop der tijden meer dan eens eropgewezen werd, dat hij te laag geworden was. De maatstaf werd echter gehandhaafd „zonder dat” (hier wordt de Nota letterlijk aangehaald) „daarbij eenige „rekening is gehouden: noch met de kwestie van vraag en „aanbod, noch met de veranderingen in de prijzen der „levensmiddelen in de kolonie, noch met den meerderen „of minderen bloei der ondernemingen, die de loonen had„den te betalen”. Hoe dat komt doet voor het oogenblik in verband met het doel van deze aanteekeningen niet ter zake, evenmin als het noodig is in te gaan op het verschijnsel, dat het gemiddeld dagloon, blijkens de loonstaten, in het Koloniaal Verslag beneden de norm bleef. Het gaat nu alleen om de opmerking, die de Raad laat volgen: dat in 1921 (ten rechte 1920) plotseling het Gouvernement ingreep, waardoor ineens de loonen werden verhoogd van $f 0.60$ op $f 0.80$ en van $f 0.40$ op $f 0.60$.

In eens: ja, bezien van wettelijk standpunt inderdaad ineens; de bedragen, die om zoo te zeggen tot toen toe wettelijk gekristalliseerd waren, werden door de nieuwe vervangen. Doch hoe stond het met de practijk?

Op den 5den Juni 1919 vergaderde te Paramaribo de Studiecommissie van het Suriname Studie Syndicaat met de leden van de destijds bestaande twee landbouwvereenigingen, onder presidium van den Leider van het Studie-syndicaat. Daar kwamen ook de loonen ter sprake. Nadat een der planters had medegedeeld, dat vele plantages voor de arbeiders rijst beschikbaar stelden tegen minder dan den kostprijs en de Voorzitter de wenschelijkheid had betoogd die loonsverhooging in het contract tot uiting te doen komen, deed een ander planter, vertegenwoordiger van de grootste onderneming, opmerken, dat men in het contract het loon dan moest vaststellen op $80 \mathrm{cts}$; „de bestaande toestand is daarmede feitelijk in "overeenstemming", voegde hij er bij. En op de nadruk- 
kelijke vraag of hij dus de zuivere dagloonen van 60 op 80 cent wilde brengen, antwoordde dezelfde: dat dit reeds bij velen geschiedde.

Ik cursiveer om er de bijzondere aandacht op te vestigen, dat die 80 cent maar niet een willekeurige uitvinding geweest zijn en dat het niet aangaat om te zeggen, dat de loonen ineens, door het ingrijpen van de Overheid, als het ware bij wijze van overval verhoogd werden. De noodzakelijkheid van eene verhooging was reeds in den kring der planters ingezien; een loon van 80 cent door hen reeds in practijk gebracht; door velen zelfs, zooals gezegd werd.

$\mathrm{Nu}$ werd het de taak van de Overheid om wat gebruik geworden was, vast te leggen, want „velen” was nog niet „allen” en het was niet toelaatbaar, dat enkelen aan hunne immigranten zouden onthouden wat velen reeds als noodzakelijk hadden erkend. Men bedenke hierbij dat de bedingen van de werkcontracten voor alle immigranten gelijk moeten zijn.

Ik ging naar Holland, onder meer om daar de belangen van den landbouw en de immigratie te bespreken. In eene vergadering met het Suriname Studie Syndicaat, op 11 Mei 1920 te 's-Gravenhage, deelde ik mijn voornemen mede om als norm voor het arbeidsloon vast te leggen 80 cent voor den man, 60 cent voor de vrouw. Nu wil ik mij niet uitsluitend beroepen op het feit, dat in die vergadering, waarin de genoemde Studiecommissie en vertegenwoordigers van landbouwbelangen in Suriname aanwezig waren, geen stem tegen dat voornemen werd aangeheven, daar ik wil aannemen, dat de aandacht hoofdzakelijk gespannen was op het voornaamste: de vraag of het Studiesyndicaat nieuwe ondernemingen in Suriname zou vestigen; maar het mag toch niet onvermeld blijven, want er werd wel degelijk over het loonvraagstuk gesproken en ik vond zelfs steun bij een der aanwezigen, die het arbeidsloon in Suriname laag noemde in vergelijking met de loonen, die in naburige landen, b.v. Britsch Guyana, werden betaald.

Toen ik in Suriname terugkeerde, was het loonvraagstuk intusschen acuut geworden. Mijn tijdelijke vervan- 
ger had besprekingen gevoerd met de besturen der beide Landbouwvereenigingen op de basis van 75 cent loon voor den man, 55 cent voor de vrouw. Overeenstemming was, althans schriftelijk, nog niet bereikt: een der vereenigingen berichtte zich haar eindoordeel voor te behouden in afwachting van de beslissing, die ik zou medebrengen aangaande de verlaging van het aandeel der planters in de aanvoerkosten van de immigranten.

Mij werden gegevens verstrekt, die duidelijk de dringende noodzakelijkheid aantoonden van eene voorziening; door den Geneeskundigen Dienst liet ik mij voorlichten aangaande de minimumbehoefte aan voedingsstoffen, ten einde te kunnen beoordeelen in hoever daaraan met het wettelijk standaardloon (c.q. 80 en 60 cent) zou kunnen worden voldaan. En toen begon het uitvoerig overleg met de Landbouwvereenigingen, waarvan de Nota niet rept. Wellicht slaat op die onderhandelingen de passage op bl. 40: „Het is ons bekend dat de toenmalige "Gouverneur zelfs nog veel verder had willen gaan" (ver„der dan 80 cent dus) „en dat alleen een eensgezind op„treden der beide plantersvereenigingen en de bedreiging „om de plantages te zullen stopzetten, waardoor alle ar„beiders geheel ten laste van het Gouvernement zouden „komen, een dergelijke ramp heeft kunnen verhoeden."

Ik ontken ten stelligste, dat de planters zulk een bedreiging tot den Gouverneur gericht hebben; het is geheel bezijden de waarheid dat zulk eene bedreiging een ramp verhoed zou hebben! Er zal nog gelegenheid zijn hier op terug te komen in het verder relaas.

De Gouverneur - zegt de Nota - had zelfs nog veel verder willen gaan. Ik begrijp wat bedoeld wordt, doch moet weer opkomen tegen de wijze van voorstelling.

Toen ik alle gegevens, die ik behoefde voor het overleg met de planters, bijeen had, riep ik de Besturen der Landbouwvereenigingen op tot eene vergadering op 6 Augustus 1920. Ik gaf daar eerst eene uiteenzetting van de, hun gunstige, beslissing in zake het plantersaandeel in de immigratiekosten en bracht daarna het loonvraagstuk aan de orde. Ik deelde hun mede, dat volgens de mij door 
het Immigratiedepartement en den Geneeskundigen Dienst verschafte gegevens, berekend naar de winkelprijzen, een Javaansch arbeider $f 7.60$, een Britsch-Indiër $f 7.20$ per week noodig zou hebben om in de meest noodzakelijke levensbehoeften te kunnen voorzien; dit zou dus neerkomen op een dagloon van $f 1.25$ voor den Javaan. Onmiddellijk wierp een der planters daartegen in: Als dat waar is, kunnen wij de zaak wel sluiten, want een dergelijk loon betalen kunnen wij nooit.

Is dat soms de bedreiging van de Nota? Dan zou ze al heel voorbarig geweest zijn, want het was pas het eerste begin van het overleg. Ik deed uitkomen, dat de man moest hebben wat noodig was voor de onmisbare eerste levensbehoeften, doch stelde daarbij dadelijk in het licht, dat er drie wegen waren, waarlangs de werkgever aan dezen eisch zou kunnen voldoen, en wel:

$1^{\circ}$. door het loon te regelen naar de noodzakelijke behoefte;

$2^{\circ}$. door verstrekking van levensmiddelen naast het loon;

$3^{\circ}$. door coöperatief levensbenoodigdheden (ook kleeren, gereedschappen, enz.) ten behoeve van de plantagearbeiders in te koopen en aan hen te verkoopen ${ }^{1}$ ), waardoor dezen verlost zouden worden van de zeer hooge prijzen van de, vaak voor vrij belangrijk bedrag verhuurde plantagewinkels, en hun loon dus grootere waarde zou krijgen.

Dit zijn de punten geweest, waarover het verder overleg geloopen heeft. Ik gaf den heeren gelegenheid om hunnerzijds met uitgewerkte voorstellen naar deze beginselen voor den dag te komen in eene tweede bijeenkomst op 24 Augustus.

Uit deze eerste vergadering moge ik nog twee punten aanstippen:

a. Ik had op den voorgrond gesteld, dat in elk geval het standaardloon op 80 cents moest worden bepaald; met andere woorden: bevestigd wat de practijk reeds als

1) Ik wist dat de planters dit reeds in overweging hadden. 
noodzakelijk had erkend. Daartegen is toen niet geprotesteerd; alleen is opgemerkt dat een hooger loon niet mogelijk was.

$b$. Ik had het denkbeeld geopperd om, met het oog op de buitengewone tijdsomstandigheden, eene tijdelijke loonstoeslag te geven, die later bij terugkeer tot een meer normalen levensstandaard weer zou kunnen vervallen. Een der aanwezige officiëele adviseurs bracht de bezwaren tegen het stelsel naar voren. En de planters zijn er hunnerzijds niet op ingegaan. Dit vermeld ik, in verband met deze passage uit de Nota:

„Dat men in Suriname op grond van tijdelijke abnor„male omstandigheden een definitieve loonsverhooging „heeft gedecreteerd, berust op hetzelfde gebrek aan in„zicht, dat men déstijds overal ter wereld heeft kunnen „constateeren”.

Het is mij een genoegen te mogen vaststellen, dat in Suriname wèl aandacht aan het vermoedelijk tijdelijk karakter van de bijzondere toestanden gegeven is en zelfs daarmede rekening is gehouden, want zooals verder uit de tot stand gekomen regeling zal blijken, bevat die regeling elementen, welke met de tijdsomstandigheden zouden wisselen. De verhooging van het standaardloon op zich zelf van 60 tot 80 cent mag niet beschouwd worden als een maatregel, waartoe alleen tijdelijke nood dwong.

Eén helft van het „dubbel verwijt" aan het Bestuur op bl. 41 der Nota is dus inderdaad ongerechtvaardigd.

De andere helft wordt nader besproken.

In de tweede bijeenkomst - die van 24 Augustus 1920 - werden de officiëele en de inmiddels door de landbouwvereenigingen samengestelde lijsten van de strict vereischte voedingsmiddelen en andere levensbenoodigdheden, tot in de kleinste bijzonderheden, wat hoeveelheid en prijzen betreft, onderzocht en uitvoerig besproken, met het gevolg dat ik ten slotte de lijsten der planters zelven kon aanvaarden, behoudens eene op beslist advies van den Geneeskundigen Dienst aangebrachte geringe uitbreiding van het voedsel-rantsoen met $\frac{1}{8}$ K.G. kabeljauw per week (waarde 9 cent). 
Het spijt mij voor den lezer dat ik in zulke kleinigheden moet afdalen, maar het is noodig om aan te toonen, dat er maar niet in het wilde gedecreteerd is, zooals de Nota zou doen vermoeden.

Ten gevolge van de voordeelen, die de immigrant zou genieten als de planters de in de lijsten opgesomde artikelen voor de daarin genoemde prijzen voor hem verkrijgbaar stelden, zou het geldloon van 80 c. voor den man en 60 cent voor de vrouw respectievelijk eene waarde krijgen van $f 1.06^{5}$ en 81 cent.

$\mathrm{Nu}$ werden echter tegen de 80 en 60 cent weer wèl bezwaren ingebracht. De Besturen verzochten om uitstel van de beslissing, ten einde eerst nog met de leden der vereenigingen te kunnen overleggen. Ik stond het toe, doch verzocht om een spoedige behandeling, daar over enkele dagen het stoomschip Madioen met immigranten van Java verwacht werd en ik niet bereid zou zijn arbeiders aan de plantages af te staan op de oude, onveranderde voorwaarden.

Een week later ontving ik van de vereenigingen het verzoek om geene andere bedingen voor de inmiddels aangekomen Javanen te stellen dan eene verhooging van den loonmaatstaf tot $f 0.75$ en $f 0.55$ zonder meer, daar anders de leden bezwaar zouden maken de immigranten aan te nemen.

Indien dit nu de ,bedreiging” mocht zijn, waarvan de Nota gewag maakt, dan was het wel een wonderlijk soort bedreiging, want de planters wisten immers reeds van mij dat ik zelf bezwaar had hun arbeiders toe te wijzen. Ik heb het dan ook niet als een bedreiging beschouwd; zij zullen het niet als een bedreiging hebben bedoeld.

Een maand lang is er nog gewikt en gewogen, overlegd, gecorrespondeerd. Eene wending bracht eene mededeeling van de Besturen, dat de leden der Vereenigingen vermoedelijk geen bezwaar zouden hebben den loonmaatstaf te verhoogen tot 80 en 60 cent, indien er genoegen mede genomen werd, dat de benoodigde artikelen niet geleverd zouden worden tegen gezetten prijs, maar tegen kostprijs, 
waarbij zij er naar zouden streven die prijs zoo laag mogelijk te doen zijn.

Ten slotte ontving ik van de Besturen het voorstel om de zaak te regelen op dezen voet:

$1^{\circ}$. standaardloonen van 80 cent en 60 cent;

$2^{\circ}$. beschikbaarstelling van rijst voor de immigranten tegen ten hoogste 12 cent per pond tot een maximum van 8 pond per week en per volwassene;

$3^{\circ}$. verkrijgbaarstelling van de vereischte andere voedingsmiddelen en artikelen tegen den laagst mogelijken kostprijs;

$4^{\circ}$. ter beschikkingstelling van $\frac{1}{4}$ akker gronds per hoofd op de plantages ten behoeve van de immigranten, voor eigen gebruik.

Dit voorstel heb ik aanvaard; begin October bereikte mij het bericht, dat de groote meerderheid der planters er zich bij had aangesloten. Toen werden de overeenkomsten der immigranten van de Madioen aldus gewijzigd, de arbeiders toegewezen, en sedert dien zijn de gemelde bedingen algemeen in de werkcontracten opgenomen.

Van deze maatregelen eischten alleen de eerste en de tweede geldelijke offers van de ondernemers, de eerste blijvend, de tweede tijdelijk. Vooral die tweede was een belangrijke tegemoetkoming voor dien tijd, waarin de rijstprijzen ongewoon opliepen; dit was dus de duurtetoeslag, het element van tijdelijke hulp in bijzonderen nood, dat volgens de Nota niet in acht genomen zou zijn. Naar gelang de toestanden en prijzen normaler werden, verloor het beding voor den planter gedeeltelijk of geheel zijne financiëele beteekenis. Reeds in den loop van 1921 begon de padi-prijs, die opgeloopen was tot 20 cent en meer per K.G., te dalen; zelfs tot 8 cent na den grooten oogst. In latere jaren schommelde hij tusschen 13 en 6 cent. Bij zulke prijzen behoeft de planter niet toe te leggen op de 12 cent. In den duursten tijd hebben sommigen, om hunne kosten te drukken, gezorgd voor een eigen aanplant.

De maatregelen, onder 3 en 4 omschreven, kostten de 
planters geen geld; met dien verstande, dat sommigen waarschijnlijk wel inkomsten gederfd zullen hebben op de verhuur van hunne plantagewinkels, toen daarin voor de eerste levensbenoodigdheden niet meer zulke abnormaal hooge prijzen mochten worden berekend. In 3 school voor de arbeiders ook een soort duurtetoeslag; van de planters vorderde de maatregel alleen samenwerking; zij sloten zich aaneen voor gezamenlijken inkoop. Gaandeweg zijn ook hierin de toestanden veranderd.

Bij 4 moet nog iets worden aangeteekend. In de Nota wordt (p. 41) gewezen op de bij-inkomsten van den arbeider: „vruchten van zijn grondje (krachtens het immi„gratie-contract heeft elke immigrant recht op $\frac{1}{4}$ akker „grond ter bebouwing voor eigen rekening), visch uit de „trenzen der onderneming enz. enz."

Gedurende het overleg met de planters werd ook van hunne zijde beroep gedaan op die bij-inkomsten. Doch wat bleek? Dat volstrekt niet op alle plantages grond voor de arbeiders beschikbaar gesteld werd; het was toen nog geen contracts-bepaling; dat is het pas bij de loonsherziening geworden. En wat het visschen aangaat (trouwens alleen in den drogen tijd mogelijk): er waren plantages, waar de ondernemer, gebruik makende van zijn recht, het verboden had.

De verplichting om een stukje grond voor den immigrant beschikbaar te stellen (dat wil zeggen - en dit geldt ook voor de andere besproken bedingen - den arbeider gelegenheid te geven er over te beschikken als hij dat wenscht), heeft vooral beteekenis voor immigranten met gezinnen.

In het voorafgaande werd alleen gesproken van de enkele individuen, de behoeften van den man, van de vrouw met een werkovereenkomst. Men bedenke echter wel, dat er dikwijls ook gezinnen bij te onderhouden zijn. Met het oog daarop is de verplichting ten aanzien van het verkrijgbaarstellen van rijst ook tot de leden van het gezin van den immigrant uitgestrekt.

$\mathrm{Nu}$ het werkelijk verloop van de nieuwe regeling is 
weergegeven, kunnen daaraan nog eenige opmerkingen naar aanleiding van enkele passages van de Nota worden vastgeknoopt.

1. Waarom werd de regeling noodig geacht - wordt gevraagd.

En het antwoord wordt al dadelijk gegeven: „Voor zoo„ver ons bekend is, hebben niet klachten van de zijde der „contractanten, niet, medische rapporten omtrent onder„voeding, of dergelijke feitelijke gegevens, doch uit„sluitend theoretische beschouwingen, gebaseerd op de „index-cijfers, den Gouverneur tot zijn optreden ge„leid”.

$\mathrm{Nu}$, mij zijn wel klachten van contractanten gerapporteerd, klachten van arbeiders in Suriname en van teruggekeerden in Indië. Een medisch onderzoek naar den voedingstoestand der immigranten is door de planters gevraagd. Toen echter de Geneeskundig Inspecteur verklaarde, dat daarmede geruime tijd gemoeid zou zijn, mocht ik niet besluiten af te wachten tot dit onderzoek zou zijn afgeloopen. Trouwens, het was niet de beslissende noch de éenige vraag of ondervoeding bestond, maar wel of de geldende loonregeling waarborgen bood, dat de arbeiders, niet alleen bij die ondernemingen, waar inderdaad de werkgevers hun er gelegenheid toe gaven - die waren er gelukkig ook - maar overal, zich op eerlijke wijze van het noodige konden voorzien. Er deden zich bedenkelijke verschijnselen voor: de menigvuldige diefstallen van voedingsgewassen, in zulk een mate, dat ik er een speciaal delict met hooge straffen van had moeten maken om dat kwaad tegen te gaan; de vele desertiën van plantagearbeiders, waarvan er waren die bij kleine landbouwers gingen werken voor hooger loon; ook was ik attent gemaakt op de vervallen kleeding.

Het is dan ook niet waar, dat ,uitsluitend theoretische beschouwingen, gebaseerd op de index-cijfers" tot maatregelen leidden. Het was anders volstrekt geen theorie alléen, dat 60 cent van 50 jaar her in 1920 minder dan 30 cent waard waren! En als uitsluitend theorie gegolden had, dan zou ik een hoogeren geldloon-maatstaf dan 80 
cent hebben moeten eischen. Nu werd gestreefd naar eene oplossing voor beide partijen.

Beide: want evenmin is het waar, - de tweede helft van het „dubbel verwijt” op bl. 41 de „veel ernstiger grief” - zooals het daar heet — „dat het Bestuur een„,zijdig de belangen der arbeiders heeft behartigd, zonder „,eenige aandacht voor de vraag of de groote landbouw de „daaruit voortvloeiende enorme verzwaring van lasten „en verhooging van den kostprijs van het product kon „dragen; zonder eenige poging te doen om een voor „,arbeiders en ondernemingen beide aannemelijke oplos"sing te zoeken."

Moet het, na het uitvoerig relaas van het verloop der onderhandelingen, nog weersproken worden? Juist omdat ik doordrongen was van de beteekenis van de zaak voor de economie van het bedrijf, heb ik den planters de volle maat van gelegenheid gegeven om zelven een systeem op te zetten en, zooals is gebleken, zij hebben er ruimschoots gebruik van gemaakt, terwijl ten slotte hunne eigen voorslagen zijn aanvaard, toen ik de overtuiging had, dat daarmede ook de belangen der arbeiders voldoende gediend werden.

In den gedachtengang van de Nota is het verklaarbaar, dat zooals daar gezegd wordt: „ook de zeer groote loons"verhooging, zooals zij ten slotte tot stand is gekomen, „,een der voornaamste oorzaken is geweest van het débâcle "van zoovele ondernemingen in de volgende jaren".

$\mathrm{Nu}$ geeft de Vereeniging voor Handel en Nijverheid in Suriname jaarlijks een uitvoerig verslag over den economischen toestand. In dat over 1921 wordt melding gemaakt van de crisis en het te niet gaan van eenige plantages; namelijk: Boxel, Johanna Catharina, de Morgenster, Vredenburg, De Vrede, Vreeland, Leonsberg, Margaretha's Gift. Als oorzaak wordt aangegeven de daling der marktprijzen van koffie en cacao; van den invloed der loonsverhooging wordt niet gesproken. Het is echter de moeite waard eens na te gaan in hoever die verhooging er invloed op gehad heeft.

Morgenster, Vredenburg en Vreeland hadden, blijkens 
de loonlijsten bij het Koloniaal Verslag, geen immigranten en kunnen dus buiten beschouwing blijven.

De Vrede en Leonsberg zijn voortgezet.

Margaretha's Gift had in 1920: één Javaanschen immigrant (70 cent dagloon), in 1919: twee! Daar zal het dus niet in het loon gezeten hebben.

Blijven over Boxel en Johanna Catharina.

Boxel betaalde in 1920 gemiddeld als loon per dag uit: 87 cent aan de mannen, 53 cent aan de vrouwen; in 1921: 84 cent en 62 cent. Dus aan de mannen minder dan vóor de invoering van de loonsverhooging.

Johanna Catharina betaalde in '20: resp. 68 en 42 cent, in 1921: 71 en 48 cent. Hier dus èn voor mannen èn voor vrouwen eene loonsstijging ( 3 en 6 cent).

Het zal worden toegegeven, dat deze voorbeelden in het besproken verband weinig zeggen.

In het verslag der Vereeniging voor Handel en Nijverheid over 1922 wordt wederom melding gemaakt van de daling der marktprijzen en er op gewezen, dat de plantages daaronder zoo zeer leden, omdat zij weinig gelegenheid gehad hadden in betere tijden reserves te maken, wat tot zekere hoogte samenhing met het werken met „dure immigranten”. Het Verslag vervolgt: „Kon men er toe besluiten den aanvoer van arbeiders voor rekening van den Staat te doen geschieden, dan zou dat aan de rentabiliteit.... zeer ten goede komen."

De Vereeniging zocht het dus niet in de loonen.

Verder wordt medegedeeld, dat Waterland, St. Barbara, Constantia en Caledonia tot stilstand of nagenoeg tot stilstand zijn gebracht.

Waterland had reeds in 1919 en 1920 geen immigranten meer; het nam er eerst weer in 1921. Vergelijking is dus niet mogelijk.

Op Constantia was het gemiddeld verdiend loon per dag: in 1920 resp. 69 en 51 c., in 1921: 77 en 59 c., in 1922: 78 en 57 c., in 1923: 72 en 65 c. (vermoedelijk nog niet gesloten).

Op Caledonia: in 1920 resp. 63 en 44 c., in 1921: 66 en 49 c., in 1922: 85 en 59 c. 
Op St. Barbara: in 1920 resp. 74 en 50 c., in 1921: 82 en 62, in 1922: 67 en 66 c., in 1923: 70 en 45 c. (als Constantia).

Het is mogelijk, dat deze drie kleine plantages, - in tegenstelling met andere gelijksoortige die zijn blijven voortbestaan, - den druk van de marktdaling niet of moeielijk tegelijk met de verhooging van den loonmaatstaf hebben kunnen dragen. Maar dan moet mij toch éen opmerking van het hart: ieder ter zake kundige weet, dat er in Suriname plantages zijn, die al vele jaren zwak staan, omdat zij in zich zelf weinig levensvatbaarheid hebben; het bedrijfsleven stelt nu eenmaal andere eischen dan vroeger en, - hoe gaarne ik ook het recht van bestaan van kleinen erken, - hare positie kan geen beletsel zijn om maatregelen in te voeren, die het algemeen belang vordert, nòch maatstaf voor de begrenzing van die maatregelen om ze als het ware kunstmatig in stand te houden.

Als ik de, zeer zeker te betreuren débâcle van alle kanten bezie, dan acht ik het minstens gewaagd om de loonsherziening „een der voornaamste oorzaken” daarvan te noemen.

Ik eindig met de herhaling van de verzekering, dat ik geenszins bedoeld heb bezwaren kenbaar te maken tegen de voorstellen van den Ondernemersraad. De Raad vraagt trouwens niet om vermindering van de bedragen van 80 en 60 cent.

De gezindheid om Suriname te helpen uit den werkelijk nijpenden economischen nood met het, naar mijne vaste overtuiging éénig doeltreffend middel: de krachtige bevordering van een breed ontwikkeld, gezond landbouwbedrijf en het daaraan verbonden immigratie-kolonisatiestelsel begroet ik volgaarne met een oprechten goeden wensch. 